\title{
Teachers' Creative Behaviors in STEAM Activities With Modular Robotics
}

\author{
Anaïs Leroy * and Margarida Romero \\ Laboratoire d'Innovation et Numérique pour l'Education (LINE), Université Côte d'Azur, Nice, France
}

As STEAM activities require both the teachers and learners to be creative, it is important to train teachers to instruct and guide creativity not only when students begin a task, but also throughout its entire process persistently to maintain creative behaviors. To assess the creative process in teacher education, a currently limited topic within the literature, we examined 37 in-service teachers, who were participating in a creative pedagogy course, through a divergent creativity test (Alternative Uses Test) and a CreaCube task (a creative problem-solving task involving modular robotics). We used CreaCube as a digital manipulative task that was performed twice to ensure the creative assessment's authenticity in relation to STEAM education. In the second execution, the participants

OPEN ACCESS

Edited by: Weihua Niu,

Pace University, United States

Reviewed by: Matthew Ryan Lavery,

South Carolina Education Oversight

Committee, United States

Macarena-Paz Celume,

Université de

Paris, France

*Correspondence:

Anais Leroy

anais.leroy@univ-cotedazur.fr

Specialty section:

This article was submitted to Educational Psychology,

a section of the journal

Frontiers in Education

Received: 15 December 2020 Accepted: 21 April 2021

Published: 05 May 2021

Citation:

Leroy A and Romero M (2021) Teachers' Creative Behaviors in

STEAM Activities With

Modular Robotics.

Front. Educ. 6:642147.

doi: 10.3389/feduc.2021.642147 did not know whether they had to reproduce the same solution or find a new one. Our results show that only a quarter of the teachers proposed new solutions during the task repetition, and that this conservative and repetitive behavior increased the task completion speed. However, this suggests that even in the context of creative pedagogy courses, teachers' tendencies to prioritize speed and the application of existing solutions tendency remains a barrier to engaging in more creative behaviors that require inhibiting previous solutions and exploring new ideas. This study sheds light on the importance of teachers experimenting with this conservative behavior bias during their training and the significance of persistently applying creative behaviors in STEAM activities. Accordingly, it is essential that teachers consider these factors when developing and delivering their courses.

Keywords: creativity, maker education, teacher education, steam, modular robotics

\section{INTRODUCTION}

As the world is rapidly changing and evolving, its citizens must prepare themselves to work in currently unknown positions, and solve many new environmental, economic, and social problems (World Economic Forum, 2020). As such, 21st century competencies such as creativity aim to develop citizen and professional opportunities in uncertain contexts (Beghetto, 2019), a goal that has increased in importance since the COVID-19 pandemic. In this context, it is crucial for students to develop their creative competency, as they are linked to transversal competencies that are considered essential for today's citizenship (Bicer et al., 2019; Kim and Choi, 2019). Creativity refers to the ability to produce new and appropriate ideas or products through different cognitive process such as divergent thinking and convergent thinking (Sternberg and Lubart, 1995). Creativity is required to solve complex problems by combining divergent thinking (idea generation) as well as convergent thinking (selecting ideas) and persevere by developing concrete outcomes (Grohman et al., 2017; Lille and Romero, 2017). Creativity engages a higher level of learning and comprehension than other 
non-creative activities, as it involves planning a main solution and developing new options by suppressing previous processes, all functions of high cognition that are primordial in the learning and development of metacognition (Benedek et al., 2012). As noted in Bloom's revised taxonomy (Krathwohl et al., 2002), this cognitive process involves according to different skills that partly follow a progression in the complexity of the underlying brain processes such as understand, apply, analyze, evaluate, and create. In education, teachers' creativity can support learners' creativity development (Davies et al., 2014). Teachers can develop their ability to support learners' creativity and innovation potentials. Creativity is not only an individual potential but can be developed as group creativity (Nijstad and de Dreu, 2002). Through group creativity children can develop their capacity to solve complex problems (Sawyer, 2006). In other words, teachers' creativity can support learners' creativity, which will be observed by their capacity to generate new and useful ideas (Runco, 2004) and artefacts (Lille and Romero, 2017).

To be competitive, learners must not only apply a program or a method, but also understand the functions of the used materials and create new uses for them for the purpose of innovation (Davies et al., 2013). In this context, the traditional approach of learning, focusing on memorization and repetition, might impede the development of creativity in educational contexts (Kaila, 2005; Azzam, 2009). Repetition is indeed essential for memorization, the basis of learning (Krathwohl et al., 2002), but learners must also be able to combine academic and general knowledge and challenge themselves to test new possibilities (Sun et al., 2020). These different learning approaches could also be related to the dual process models opposing two cognitive systems (Kahneman, 2011; Houdé and Borst, 2014): a fast and automatic processing, mainly based on prior knowledge (the "conservative" one), and a more effortful, controlled processing system (here the "creative" one).

For several years, researchers and practitioners have placed an emphasis on the need to develop these transversal competences, but the integration of creativity in pedagogical programs is not yet well-defined and differs depending on countries (Shaheen, 2010). For a successful integration, teachers must have the proper training to teach creativity and create learning activities allowing their learners to develop their creativity. In the short term, including creative learning activities into the classroom can reduce drop out rates and lack of interest in certain school subjects, such as science and mathematics (Falls, 2020). In the long term, creative learning activities can develop transversal competencies aiming to increase employment opportunities and inclusivity in STEM careers (Daker et al., 2020).

Based on these factors, it becomes essential to address several gaps. Firstly, some teachers may be very creative in their daily lives and hobbies but remain rooted in a traditional vision of teaching that focuses on learning approaches based on memorization and repetition (Runco et al., 2017). In fact, despite the importance of creativity in today's citizenship, teacher education's instructions on teacher creativity are applied in different ways depending on the teacher competency frameworks worldwide. As Kaufman et al. (2017) noted, creativity is domain dependent. Thus, the traditional teaching approaches based on memorization and repetition does not support a creative pedagogy context in which the learners can develop transversal competencies (Dorier and García, 2013).

To support learners' creativity skills, as a form of problem solving (Treffinger and Isaksen, 2005), different learning activities have been introduced under the umbrella of STEAM. The recent integration of the "A" (Arts) in Science, Technology, Engineering, Arts, and Mathematics (STEAM) education highlighted the need for developing arts and humanities, as well as creativity, in school programs. In fact, the arts incorporate different competencies that improve learners' motivation, heighten their interests in the sciences, and develop their critical thinking and innovation (Conradty et al., 2020). Moreover, Card and Payne (2020) support the integration of the creative and humanistic side of the A in STEAM to develop girls' interests in technological domains and attempting to limit the disproportionate gender distribution in scientific and digital professions. Furthermore, we should consider socioeconomic gaps in digital literacy. To address these educational challenges, STEAM learning activities could support the creativity competency while developing the digital literacy in creative learning activities (Romero et al., 2017).

In Malaysia, creative mathematics teaching aims to contribute to the objectives of the Program for International Student Assessment and Trends in Mathematics and Science Study but requires establishing a new approach to develop teachers' creative behaviors (Mariani and Ismail, 2015). In France, the 2018 competency frameworks of the primary and secondary education curricula integrated problem-solving skills and creativity, as transversal competencies. To guide learners in this process and regulate their own creativity, teachers should develop an awareness of this competence by combining existing knowledge to foster thought and create new learning and regulatory activities to support the learning objectives (Reilly et al., 2011; Cassone et al., 2020). They can support creativity and teach ways to creatively solve problems using digital technologies to increase the potential affordances and alternative uses for the available tools (Harris and de Bruin, 2018). However, most tests created to evaluate creativity are based on the individual measure of divergent thinking using familiar objects, but creativity also involves convergent thinking processes, especially when creating a physical artefact, as seen in maker education activities, such as educational robotics (Riikonen et al., 2020). Thus, to support the development of creativity competency through STEAM education, we must guide learners' divergent and convergent thinking processes, establish strategies to create solutions using technological materials, and develop students' critical thinking to help them understand how to not only use a certain technology, but also create something new with it.

As such, our study analyzes the cognitive modes in teacher education and identify the required factors that would effectively help teachers develop their creative competency, beyond unitary interventions (Romero et al., 2019). Specifically, we examined teachers in continuing education, who voluntarily enrolled in a creativity course, and analyzed their divergent thinking through the Alternative Uses Test (AUT) and their convergent thinking with CreaCube (problem-solving task that was identically repeated twice). We hypothesize that, despite the course's focus 


\section{CreaCube Task}
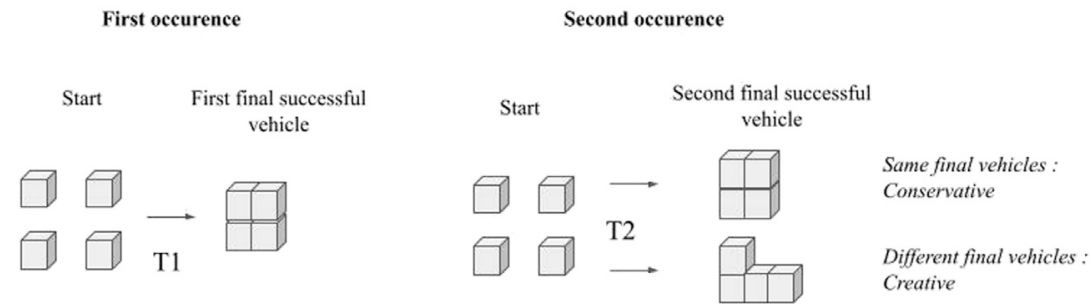

FIGURE 1 | The two stages of the CreaCube task.

on creativity and the study's initial divergent thinking test, most of the participating teachers will offer the same solution for the repeated CreaCube tasks, regardless of their AUT accomplishments. Thus, we believe that the default cognitive mode is conservative, as our teaching and learning habits are to repeat the same memorized solution to solve a task. Inhibiting this default mode is difficult, and teachers must have a certain awareness of this tendency to think and teach differently (i.e., corresponding to meta-cognitive knowledge in the Revised Taxonomy of Krathwol, 2002). As such, we first evaluate the teachers' behavioral profiles, termed conservative if they repeat the same solution or creative if they try to find a new one. Then, we explore if their behavioral profiles are linked to their creative profiles (AUT), the time required to complete the CreaCube tasks, or their cognitive profiles (their understanding of the second instruction).

\section{MATERIALS AND METHODS}

\section{Participants}

Our final sample included 37 primary education teachers in their third year of teaching who were participating in a continuous education training course on the creative uses of digital technologies. They all provided informed consent and voluntarily participated in this study (Mean age $=33.1$; $\mathrm{SD}=$ $6.8 ; 32$ females). This study was approved by the Comité d'Éthique pour les Recherches non-Interventionnelles (ethics committee) of the Université Côte d'Azur in France.

\section{Materials}

\section{Alternative Use Test}

In this divergent creativity test, the participants had to write multiple ideas for using three familiar objects (a box, can, and chair) and we allocated $2 \mathrm{~min}$ for each object (total duration $=6 \mathrm{~min}$ ). This task allowed us to assess creativity in terms of fluency (total number of differing ideas), flexibility (number of different categories), and originality (responses given by less than $5 \%$ of all participants, determined through answer comparisons). For example, with regards to using a box, if a participant responded with "I can use it to store clothes and shoes, and to create a robot costume," he/she will receive three points for fluency (three different answers) and two points for flexibility ("storing" clothes and shoes are the same category). Finally, as in other study (Radel et al., 2015) we scored one point for each answer, and then summed and averaged the scores for each of the three components and each participant.

\section{The CreaCube Task: Modular Robotics}

The CreaCube task (Romero et al., 2018) is a problem-solving task that uses a manipulative robotic cube from the Cubelets Modular Robotic set (https://www.modrobotics.com/cubelets/). It requires participants to create a vehicle that could move by itself from one point to another with the use of four cubes, chosen for their different affordances (technological and material). Before starting the activity, the examiner explained that the participants' hands would be filmed (informed consent provided). There were no time constraints and although the participants did not receive any help, they were free to listen to the recorded instructions as much as they wished: "build an autonomous vehicle that moves from a starting red point to the finishing black point." As these cubes are generally unfamiliar objects, the participants must explore them and try different associations to resolve the task. Each cube has its own characteristics (i.e., wheels, sensor, battery, or inverter) and the way the cubes are connected can help or impede the task's resolution. The different associations create different "configurations," meaning different global forms (Figure 1), and some are successful, while others are not, due to, for example, imbalances or poor technological connections. A total of 12 successful configurations are possible, the number of functional combinations is thus limited, which makes it possible to study their frequency of occurrence but remains large enough to allow participants to explore different solutions. We asked the participants to resolve this CreaCube task twice: once the first endeavor was finished (A1), we situated the cubes in the same position as in the beginning of the first activity and with we gave the same instructions, without commenting or disclosing any further information. Therefore, participants were free to decide if they wanted to be creative and attempt a new solution (find a new successful configuration for resolving the task), or be conservative and resolve the task with the same configuration. Then, we noted if the second final successful vehicle was the same as or different from the first, and recorded the time needed to resolve the first and second CreaCube tasks. Notice that they were no timer, the time was recorded during the viewing of the videos in order not to put any time pressure on the task. If a time pressure can be observed in the participants, it comes from the time felt, perceived by the participants themselves without any external reference. 

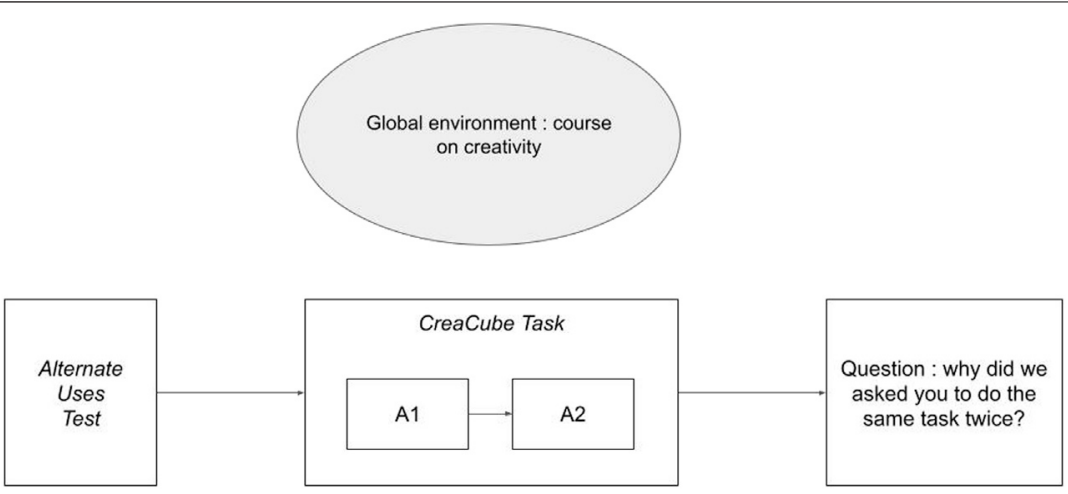

FIGURE 2 | Protocol progress.

TABLE 1 | Correlation scores between the AUT task component, behavioral profiles (CreaCube task-creative or conservative), and cognitive profiles (answers to why the CreaCube activity was repeated).

\begin{tabular}{|c|c|c|c|c|c|}
\hline & & AUT_Fluidity & AUT_Flexibility & AUT_Originality & Behavioral profile \\
\hline AUT_Flexibility & $\begin{array}{l}\text { Pearson's r } \\
p \text {-value }\end{array}$ & $\begin{array}{c}0.777 \\
<.001^{\star \star \star}\end{array}$ & $\begin{array}{l}- \\
-\end{array}$ & & \\
\hline AUT_Originality & $\begin{array}{l}\text { Pearson's } r \\
p \text {-value }\end{array}$ & $\begin{array}{c}0.484 \\
0.002^{\star \star}\end{array}$ & $\begin{array}{l}0.400 \\
0.014^{\star}\end{array}$ & $\begin{array}{l}- \\
-\end{array}$ & \\
\hline Behavioral Profile & $\begin{array}{l}\text { Pearson's } r \\
p \text {-value }\end{array}$ & $\begin{array}{l}0.042 \\
0.805\end{array}$ & $\begin{array}{l}0.078 \\
0.647\end{array}$ & $\begin{array}{l}0.001 \\
0.996\end{array}$ & $\begin{array}{l}- \\
-\end{array}$ \\
\hline
\end{tabular}

\section{Procedure}

The tests had taken place during a course on the creative uses of digital technology. The participants of this course were proposed to participate in a study on creativity without explaining further at this stage the objectives of this research. the participants were free to refuse to participate in the study and have the possibility to refuse to have their data recorded and used in the study. We proposed the first task, the AUT (Figure 2), to all the participants at the same time and in the same space, but they had to complete it individually. Once the AUT was finished, each participant individually resolved the CreaCube problem-solving task outside the classroom. Participants can do the task without any time restriction and are not aware of the time they engage in the task. Once the two CreaCube activities were finished, the experimenter asked verbally to the participants to answer the following questions: "in your opinion, why did we ask you to complete the same task twice?" and "what were your main difficulties to resolve the task?". The experimenter transcribed the participants answers. It is important to keep in mind that we conducted the study during a training course on digital creativity, therefore the participants were in a context directly related to creativity and thus to the test task.

\section{Data Analysis}

In order to test our hypothesis, we analyzed different data: 1) the scores for the different AUT components, examining fluidity, flexibility, and originality (creative profile); 2) CreaCube task repetition comprehension (cognitive profile), 3) the time required to finish the first and second CreaCube tasks, establishing the "time optimization" variable (the second activity's duration minus the first activity's duration); and 4) the creative or conservative categorizations, based on the differences or similarities between the two CreaCube vehicles (behavioral profile). Then, we determined if the behavioral profiles were linked to the creative profiles, to the time optimization variable, and/or to the cognitive profiles.

\section{RESULTS}

We conducted all statistical and graphical analyses with an open source statistical analysis program: Jamovi (version 1.1.9).

\section{Realization of the CreaCube Tasks}

Most participants had the same configurations for the first and second CreaCube task vehicles (27 participants), with only 10 proposing a new solution. We found correlations between the CreaCube solution methods (behavioral profilescreative or conservative), the AUT scores, and the final question answers (cognitive profiles) (Table 1). However, there was no relationship between the AUT's creativity 


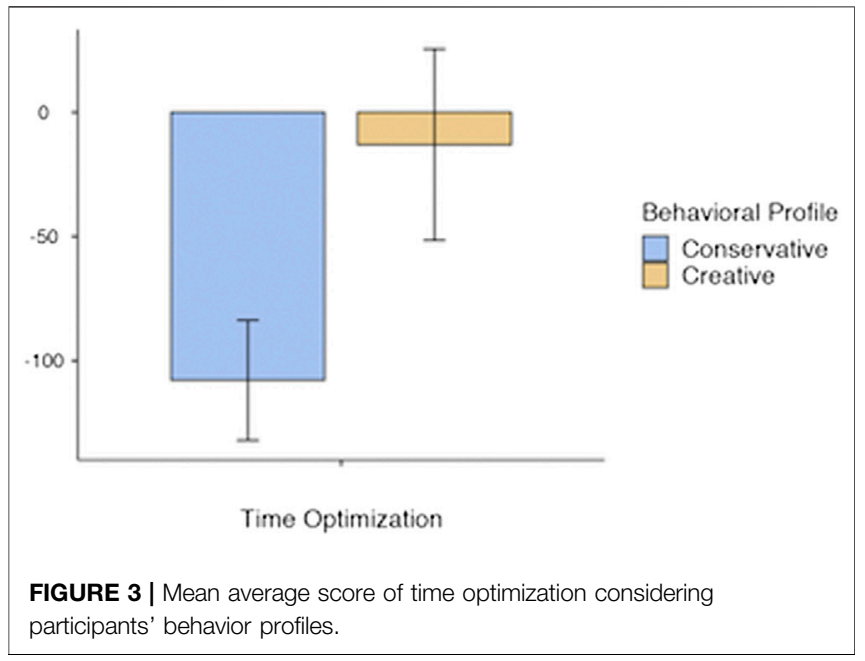

evaluations and the CreaCube's creative behaviors (all $r<0.1$; all $p \geq 0.647$ ).

\section{Differences in the Duration of the Second CreaCube Task Compared to the First}

We verified that the time optimization variable was normally distributed (Shapiro-Wilk test), and as this was not the case ( $p<$ 0.001 ), we used non-parametric tests. We ran a Kruskal-Wallis test with behavioral profile as the fixed factor and time optimization as the dependent variable, finding a significant time difference between the two CreaCube activities, $\chi^{2}$ $(1,36)=5,57 ; p=0.018$. As expected, the conservative participants needed less time to successfully complete the second activity, compared to the first (108s on average $+/-24$; Figure 3), while the creative participants' time variations between the two tasks were minimal ( $-13 \mathrm{~s}$ on average, SE: 35$)$. We also found a similar exerted effort when the participants were creative during the second activity.

\section{Answers Regarding the CreaCube Activity's Repetition}

The participants proposed two general answers: the second activity serves to determine if participants have correctly memorized how to resolve the task (15 participants) or to explore if they can find a new way to resolve problem (22 participants). These answers match the conservative and creative cognitive profiles, respectively. As seen in Table 1, we found a significant correlation between the cognitive and behavioral profiles. Indeed, all the participants showing conservative behaviors answered that the reason for the repetition was to test their memorization. Within those who answered that the repetition was to show if they could find a new solution, almost half created a new vehicle (10 participants), but the other 12 participants offered the same solution a second time (Figure 4), suggesting that in addition to creative intentions, creative execution requires other competencies.

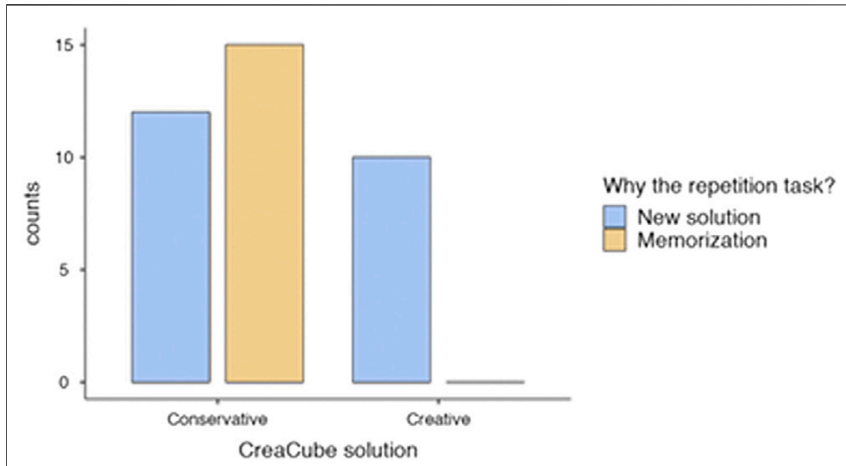

FIGURE 4 | Proportion of participants with regards to CreaCube task solutions and why the task was repeated.

\section{DISCUSSION}

\section{Initial Conservative Bias and Hindrances to Creativity}

Overall, the results of this study show that only one quarter of the participants, approximately, solved the second identical task in a creative way by proposing a new solution, and most simply replicated the first solution. The results also reveal that the attitude with which an activity is approached influences its realization. Although the course the participants were taking focused on creativity, more than $40 \%$ believed that asking them to resolve the task a second time was meant to test their memorization. Despite being on a creativity course, the memorization hypothesis for the task repetition shows an important number of participants to lack a creative opportunity for the task repetition. This conservative cognitive profile is linked to traditional visions of teaching (i.e., learning by repetition, memory), but trying new solutions allows for more exploration, expands understandings of the used materials, and promotes critical thinking. The results of this study also show that the conservative's participants spend less time for the repetition of the CreaCube task although the creative ones need approximatively the same time to resolve the task with a new solution. Therefore, it's seems that to be creative, one must go further than simply remembering and reproducing the initial steps or the effortless way to address a problem. In the context of this study, it is necessary to really understand the features of the robotic cubes, how their relative positions affect the configuration, and what aspects (e.g., balance, direction of the wheels, etc.) must be considered to successfully complete the task. It is important to remember that the teachers chose to attend a course on creativity, among the various training topics offered by the in-service training program including other domain-specific courses in mathematics and language. Thus, we can assume that they already understood the importance of developing creativity competency among their learners. The in-service teachers were engaged in a full day of creative learning activities engaging different uses of technologies. Despite the in-service teachers selected the creative pedagogy course, the majority repeated the same solution, highlighting the creative hindrance issues. 
The teachers' feedback at the end of the study revealed that those who tried to reproduce the first vehicle from memory were indeed performance oriented, but they also described an initial fear of not being able to find a new solution, because they did not feel confident in their logical thinking abilities or competent in manual activities. Some of the teachers also reported that the social pressure of under-performing in terms of problem-solving speed and overall failure inhibited their creativity when repeating the task. Finally, the participants who answered that the repetition of the task was made to observe if they managed to build a new vehicle but who proposed in the end the same solution as in the first occurrence of the task, tried to find a new solution, they spent time on it and after a while decided to come back on their first solution. The pressure of being too slow and not succeeding rapidly to solve in a new way the second repetition of the task, made them abandon their creative will to return to a more conservative, simpler, already known behaviour.

This brings us to an important point: even when teachers see a task repetition as an opportunity to be creative, we need to encourage them to persevere. There is a need to encourage and strengthen teachers' creativity to support learners' creativity. Creative competence requires one to take the time to test other solutions, instead of quickly repeating the known solution, and to overcome the fear of failure and the self-efficacy threats that some teachers experience when facing problemsolving tasks with unknown technologies.

To go further than the direct applications of this study, another important point involves the link between creativity and different disciplines, especially in interdisciplinary projects. To remove creativity's previous restriction to the artistic domains, we must also develop creative approaches in science and technology activities, or even in interdisciplinary STEAM activities. In other words, to overcome the traditional dichotomy between the scientific and artistic domains, we must underline the creative processes, engaging divergent and convergent thinking, that appear in different domains. In this study, the participants proposed many different ideas (divergent thinking) when writing about the different uses of familiar objects (AUT), but when solving the same problem twice, the majority repeated the same solution. This result suggests a restrictive view of task or domain specific for creativity, means that in this particular task the participant could give lot of different and non-usual answers but in a more logical, technological or more "academic" domain I stay in a classical, repetitive solution. Indeed, this highlight the need to change this mindset of speed and repetition that emerges in classical teaching. Only by overcoming this mindset can we be able to engage in creative activities with a perspective that will contribute to developing more creative competencies in the different disciplines required for citizens and professionals living in today's society (European Commission, 2017).

\section{How to Teach Creativity}

It seems that to teach creativity, teachers must overcome their performance orientation to engage in task repetitions as an opportunity to be creative. Instead, repetition with an intentional focus on novel solutions and creative exploration is needed to overcome performance orientation. Thus, it is necessary to guide them in this transformative professional development and help them first develop their own creative competencies. Supporting teachers in overcoming their temporal performance orientations and their fears related to technology can contribute to the development of new approaches that would support teachers' acquisitions of creative competency through long-term mindset adjustments. In this sense, the results of our study are aligned with (Beghetto and Kaufman, 2014) practical insights, including the need to integrate creativity in all learning activities during the entire year, instead of only teaching it as a specific activity. In other words, creativity competence development for learners of all ages, including preservice and in-service teachers, should be developed through long term interventions that embrace a creative pedagogy, instead of specific creativity tasks. Ironically, it is by repeating creative activities, but crucially with an intentional focus on the research of novelty, creativity, that we will be able to overcome the conservative perspective of repetition for memorization and learning that is still predominant in worldwide educational practices (Sawyer, 2019). Additionally, teachers can design STEAM activities to support the development of learners' creativity in different disciplinary domains (Craft, 2005). They can create interdisciplinary learning activities that would help students improve their capacities to solve complex problems that require an integrative interdisciplinary approach, such as sustainable development goals or other societal challenges in today's society.

To conclude, our objective was to focus on the effects of an short and easy to implement (few materials needed) training session that allows teachers to increase their awareness of the necessary prerequisites for the creative process. Therefore, one of the strengths of this study is that the participants directly experienced the difficulties in acquiring a creative mindset, and this direct experience can not only enhance the learning process (Stull et al., 2018; Castro-Alonso et al., 2019; Kubik et al., 2020), but also improve creativity itself (for a review; Frith et al., 2019). By directly engaging in the CreaCube activity, teachers' awareness on the conservative behavior bias will increase and allow them to make changes in their teaching, especially with regards to improving divergent thinking, testing new solutions (Beghetto, 2010; Beghetto and Kaufman, 2014), and going beyond memorization through exact repetition. Future studies should aim to advance in the confirmation of these results within different modalities of the CreaCube task but also with other STEAM tasks aiming to engage participants in the development of their creativity.

\section{DATA AVAILABILITY STATEMENT}

The raw data supporting the conclusions of this article will be made available by the authors, without undue reservation.

\section{ETHICS STATEMENT}

The studies involving human participants were reviewed and approved by Comité d'Ethique pour les Recherches Non 
Interventionnelles, CERNI, 2019-6, Université Côte d'Azur. The patients/participants provided their written informed consent to participate in this study.

\section{AUTHOR CONTRIBUTIONS}

$\mathrm{AL}$ and MR conceived the study, the theoretical framework and methodology. MR directed the project and task protocol.

\section{REFERENCES}

Azzam, A. M. (2009). Why Creativity Now? A Conversation with Sir Ken Robinson. Educ. Leadersh. 67 (1), 22-26.

Beghetto, R. A., and Kaufman, J. C. (2014). Classroom Contexts for Creativity. High Ability Stud. 25 (1), 53-69. doi:10.1080/13598139.2014.905247

Beghetto, R. A. (2010). "Creativity in the Classroom," in The Cambridge Handbook of Creativity. Editors J. C. Kaufman and R. J. Sternberg (Cambridge, UK: Cambridge University Press), 447-463.

Beghetto, R. A. (2019). "Structured Uncertainty: How Creativity Thrives under Constraints and Uncertainty," in Creativity under Duress in Education? (Cham: Springer), 27-40. doi:10.1007/978-3-319-90272-2_2

Benedek, M., Franz, F., Heene, M., and Neubauer, A. C. (2012). Differential Effects of Cognitive Inhibition and Intelligence on Creativity. Personal. Individual Differences 53 (4), 480-485. doi:10.1016/j.paid.2012.04.014

Bicer, A., Lee, Y., Capraro, R. M., Capraro, M. M., Barroso, L. R., and Rugh, M. (2019). "Examining the Effects of STEM PBL on Students' Divergent Thinking Attitudes Related to Creative Problem Solving," in 2019 IEEE Frontiers in Education Conference (FIE), Cincinnati, Ohio, USA, 16-19 October 2019, 1-6.

Card, D., and Payne, A. A. (2020). High School Choices and the Gender Gap in STEM. Econ. Inq. 59, 9-28. doi:10.1111/ecin.12934

Cassone, L., Romero, M., and Esfahani, S. B. (2020). Group Processes and Creative Components in a Problem-Solving Task with Modular Robotics. J. Comput. Educ., 1-21. doi:10.1007/s40692-020-00172-7

Castro-Alonso, J. C., Paas, F., and Ginns, P. (2019). "Embodied Cognition, Science Education, and Visuospatial Processing," in Visuospatial Processing for Education in Health and Natural Sciences. Editor J. C. Castro-Alonso (Cham: Springer International Publishing), 175-205. doi:10.1007/978-3-03020969-8_7

Conradty, C., Sotiriou, S. A., and Bogner, F. X. (2020). How Creativity in STEAM Modules Intervenes with Self-Efficacy and Motivation. Educ. Sci. 10 (3), 70. doi:10.3390/educsci10030070

Craft, A. (2005). Creativity in Schools: Tensions and Dilemmas. London: Routledge. doi:10.4324/9780203357965

Daker, R. J., Cortes, R. A., Lyons, I. M., and Green, A. E. (2020). Creativity Anxiety: Evidence for Anxiety that Is Specific to Creative Thinking, from STEM to the Arts. J. Exp. Psychol. Gen. 149 (1), 42-57. doi:10.1037/xge0000630

Davies, D., Jindal-Snape, D., Collier, C., Digby, R., Hay, P., and Howe, A. (2013). Creative Learning Environments in Education-A Systematic Literature Review. Thinking Skills and Creativity 8, 80-91. doi:10.1016/j.tsc.2012.07.004

Davies, D., Jindal-Snape, D., Digby, R., Howe, A., Collier, C., and Hay, P. (2014). The Roles and Development Needs of Teachers to Promote Creativity: A Systematic Review of Literature. Teach. Teach. Educ. 41, 34-41. doi:10.1016/j. tate.2014.03.003

Dorier, J.-L., and García, F. J. (2013). Challenges and Opportunities for the Implementation of Inquiry-Based Learning in Day-To-Day Teaching. ZDM Maths. Educ. 45 (6), 837-849. doi:10.1007/s11858-013-0512-8

European Commission (2017). European Framework for the Digital Competence of Educators (DigCompEdu), JRC Science for Policy. Report no. EUR 28775 EN. Available at: http://publications.jrc.ec.europa.eu/repository/bitstream/ JRC107466/pdf_digcomedu_a4_final.pdf (Accessed April 15, 2021)

Falls, Z. (2020). Beyond Boundaries: Pre-service Teachers' Experiences of Transdisciplinary Education via STEAM Making Projects. JCMST 39 (1), 19-31.
AL carried out the data collection and performed the data analysis.

\section{FUNDING}

This work was supported by the Agence Nationale de la Recherche (ANR) in France (ANR-18-CE38-0001).

Frith, E., Miller, S., and Loprinzi, P. D. (2019). A Review of Experimental Research on Embodied Creativity: Revisiting the Mind-Body Connection. J. Creat. Behav. 54, 767-798. doi:10.1002/jocb.406

Grohman, M. G., Ivcevic, Z., Silvia, P., and Kaufman, S. B. (2017). The Role of Passion and Persistence in Creativity. Psychol. Aesthetics, Creativity, Arts 11 (4), 376-385. doi:10.1037/aca0000121

Harris, A., and de Bruin, L. R. (2018). Secondary School Creativity, Teacher Practice and STEAM Education: an International Study. J. Educ. Change 19 (2), 153-179. doi:10.1007/s10833-017-9311-2

Houdé, O., and Borst, G. (2014). Measuring Inhibitory Control in Children and Adults: Brain Imaging and Mental Chronometry. Front. Psychol. 5, 616. doi:10. 3389/fpsyg.2014.00616

Kahneman, D. (2011). Thinking, Fast and Slow. New York, NY: Macmillan

Kaila, H. L. (2005). Democratizing Schools across the World to Stop Killing Creativity in Children: an Indian Perspective. Counselling Psychol. Q. 18 (1), 1-6. doi:10.1080/09515070500099728

Kaufman, J. C., Glăveanu, V. P., and Baer, J. (Editors) (2017). The Cambridge Handbook of Creativity across Domains (Cambridge: Cambridge University Press).

Kim, H., and Choi, S. Y. (2019). The Effects of Instructional Strategies Using the Process of Procedural Thinking on Computational Thinking and Creative Problem-Solving Ability in Elementary Science Classes. J. Sci. Educ. 43 (3), 329-341. doi:10.21796/jse.2019.43.3.329

Krathwohl, D. R. (2002). A Revision of Bloom's Taxonomy: an Overview. Theor. Into Pract. 41 (4), 212-218. doi:10.1207/s15430421tip4104_2

Kubik, V., Jönsson, F. U., de Jonge, M., and Arshamian, A. (2020). Putting Action into Testing: Enacted Retrieval Benefits Long-Term Retention More Than Covert Retrieval. Q. J. Exp. Psychol. 73 (12), 2093-2105. doi:10.1177/ 1747021820945560

Lille, B., and Romero, M. (2017). Creativity Assessment in the Context of MakerBased Projects. Des. Tech. Educ. Int. J. 22 (3), 32-47.

Mariani, A., and Ismail, Z. (2015). The Elements of Teachers' Competency for Creative Teaching in Mathematics. Int. Educ. Stud. 8 (13), 93-97. doi:10.5539/ ies.v8n13p93

Nijstad, B. A., and de Dreu, C. K. W. (2002). Creativity and Group Innovation. Appl. Psychol. 51 (3), 400-406. doi:10.1111/1464-0597.00984

Radel, R., Davranche, K., Fournier, M., and Dietrich, A. (2015). The Role of (Dis) inhibition in Creativity: Decreased Inhibition Improves Idea Generation. Cognition 134, 110-120. doi:10.1016/j.cognition.2014.09.001

Reilly, R. C., Lilly, F., Bramwell, G., and Kronish, N. (2011). A Synthesis of Research Concerning Creative Teachers in a Canadian Context. Teach. Teach. Educ. 27 (3), 533-542. doi:10.1016/j.tate.2010.10.007

Riikonen, S., Seitamaa-Hakkarainen, P., and Hakkarainen, K. (2020). Bringing Maker Practices to School: Tracing Discursive and Materially Mediated Aspects of Student Teams' Collaborative Making Processes. Intern. J. Comput.-Support. Collab. Learn. 15 (3), 319-349. doi:10.1007/s11412-020-09330-6

Romero, M., Lille, B., and Patiño, A. (2017). Usages créatifs du numérique pour l'apprentissage au XXIe siècle Québec: PUQ.

Romero, M., David, D., and Lille, B. (2018). "CreaCube, a Playful Activity with Modular Robotics," in International Conference on Games and Learning Alliance, December (Cham: Springer), 397-405.

Romero, M., Arnab, S., De Smet, C., Mohamad, F., Minoi, J. L., and Morini, L. (2019). Assessment of Co-creativity in the Process of Game Design. EJEL 17 (3), 199-206. doi:10.34190/jel.17.3.003 
Runco, M. A., Acar, S., and Cayirdag, N. (2017). A Closer Look at the Creativity Gap and Why Students Are Less Creative at School Than outside of School. Thinking Skills and Creativity 24, 242-249. doi:10. 1016/j.tsc.2017.04.003

Runco, M. (2004). "Personal Creativity and Culture," in Creativity: When East Meets West. Editors S. Lau, A. N. N. Hui, and G. Y. Chak (Singapore: World Scientific Publishing), 9-21. doi:10.1142/9789812567192_0002

Sawyer, R. K. (2006). Educating for Innovation. Thinking Skills and Creativity 1, 41-48. doi:10.1016/j.tsc.2005.08.001

Sawyer, R. K. (2019). The Creative Classroom: Innovative Teaching for 21st-Century Learners. New York, NY: Teachers College Press.

Shaheen, R. (2010). Creativity and Education. CE 01 (3), 166-169. doi:10.4236/ce. 2010.13026

Sternberg, R. J., and Lubart, T. I. (1995). Defying the Crowd: Cultivating Creativity in a Culture of Conformity. New York, NY: Free Press.

Stull, A. T., Gainer, M. J., and Hegarty, M. (2018). Learning by Enacting: the Role of Embodiment in Chemistry Education. Learn. Instruction 55, 80-92. doi:10. 1016/j.learninstruc.2017.09.008

Sun, M., Wang, M., and Wegerif, R. (2020). Effects of Divergent Thinking Training on Students' Scientific Creativity: The Impact of Individual Creative Potential and Domain Knowledge. Thinking Skills and Creativity 37, 100682. doi:10. 1016/j.tsc.2020.100682

Treffinger, D. J., and Isaksen, S. G. (2005). Creative Problem Solving: the History, Development, and Implications for Gifted Education and Talent Development. Gifted Child. Q. 49 (4), 342-353. doi:10.1177/ 001698620504900407

World Economic Forum (2020). The Future of Jobs Report 2020. Geneva, Switzerland: World Economic Forum. http://www3.weforum.org/docs/WEF_ Future_of_Jobs_2020.pdf.

Conflict of Interest: The authors declare that the research was conducted in the absence of any commercial or financial relationships that could be construed as a potential conflict of interest.

Copyright (c) 2021 Leroy and Romero. This is an open-access article distributed under the terms of the Creative Commons Attribution License (CC BY). The use, distribution or reproduction in other forums is permitted, provided the original author(s) and the copyright owner(s) are credited and that the original publication in this journal is cited, in accordance with accepted academic practice. No use, distribution or reproduction is permitted which does not comply with these terms. 